\title{
ANALISIS CEK LIST KESELAMATAN DAN KESEHATAN KERJA DI LABORATORIUM BIOLOGI FMIPA UNNES
}

\author{
RIA IKA MAHARANI'), FITRI ARUM SASI ${ }^{2}$ \\ ${ }^{1 *), 2}$ Laboratorium Biologi FMIPA UNNES, Semarang , 50229 \\ *) Email : ria.ika@mail.unnes.ac.id*
}

\begin{abstract}
ABSTRAK
Keselamatan dan kesehatan kerja di laboratorium menjadi sangat penting diperhatikan mengingat laboratorium memiliki nilai risiko kecelakan yang tinggi. Penilaian risiko kecelakaan ini berdasarkan dari beragamnya komponen yang ada di laboratorium, seperti bahan kimia, peralatan, sarana penunjuang serta pengguna. Dengan tingkat risiko yang tinggi tersebut maka penerapan keselamatan dan kesehatan kerja perlu dilakukan dengan cara pemantauan dan penilaian. Tujuan dari penelitian ini untuk menganalisis keselamatan dan kesehatan kerja di laboratorium biologi berdasarkan cek lis acuan keselamatan dan kesehatan kerja. Metode yang dipakai adalah deskriptif dalam bentuk kuisioner dengan analisis data menggunakan kategori berdasarkan nilai normatif yaitu $x \geq 67,5$ (kategori sangat baik), $45 \leq x<67,5$ (kategori baik), 22,5 $\leq$ $\mathrm{x}<45$ (kategori cukup baik) dan $\mathrm{x} \leq 22,5$ (kategori tidak baik). Kesimpulan dari hasil penelitian berdasarkan analisis cek list keselamatan dan kesehatan kerja di laboratorium biologi adalah kategori baik dengan rata skor 57,28. Hal ini menunjukan berdasarkan matrik acuan cek list keselamatan dan kesehatan kerja di laboratorium yang terdiri atas layout laboratorium, kantor, alat pelindung diri, kebersihan, alat darurat, bahan kimia, alat gelas dan kelistrikan telah dipenuhi dengan baik.
\end{abstract}

Kata Kunci : keselamatan dan kesehatan kerja, laboratorium, cek list

\section{ABSTRACT}

Occupational safety and health in the laboratory becomes very important considering the laboratory has a high risk of accident. Risk assesment of accidents in the laboratory based of many components, such as chemicals, equipment, supporting factors and users. As the high level of risk, the application of occupational safety and health needs to be monitored and assessed. The purpose of this study was to analyze the safety and health of the laboratory in biology based on the check list of safety and health guidance. The used method is descriptive in the form of questionnaires with data analysis using very good, good, enough, and bad categories based on normative values which are $\mathrm{x} \geq 67.5,45 \leq \mathrm{x}<67.5,22.5 \leq \mathrm{x}<45$ and $\mathrm{x} \leq$ 22.5 respectively. The conclusion of the research is occupational safety and health in the biology laboratory categorized in the good category with the average score are 57.28. The calculation based on the reference matrix of safety and health check list in the laboratory consisting of laboratory layout, office, personal protective equipment, hygiene, emergency tool, chemicals, glassware and electricity have been done well.

Key Words : occupational safety and health, laboratory, check list

\section{Pendahuluan}

Laboratorium merupakan sarana dalam proses pembelajaran untuk pengembangan hands-on activity dan peningkatan minds-on skills. Pengetahuan dapat berasal dari penggunaan berbagai macam keterampilan dan penerapan sikap ilmiah pada proses praktikum di laboratorium. Beragamnya kegiatan yang dilakukan di laboratorium menuntut ketersedian sarana dan prasaran yang lengkap. Komponen yang wajib ada adalah peralatan, bahan dan sarana pelengkap (air dan listrik).

Kegiatan yang dilakukan di laboratorium dengan komponen yang ada memiliki risiko kerja. Risiko kerja yang ada di laboratorium memiliki tingkat risiko tinggi karena penggunaan bahan kimia berbahaya, peralatan dengan tingkat penggunaan sulit serta penggunaan sarana pendukung seperti listrik. Untuk meminimalkan risiko kecelakan kerja yang terjadi maka perlu dilakukan penerapan keselamatan dan kesehatan kerja di laboratorium.
Kesehatan dan keselamatan kerja disingkat K3 memiliki tujuan untuk melindungi tenaga kerja serta karya dan budaya, menggunakan ilmu pengetahuan dan pemikiran dalam menciptakan kondisi ditempat kerja melalui penerapan teknologi pencegahan kecelakaan dengan mengikuti standar dan peraturan perundangan yang berlaku serta teratur pelaksanaannya (Hati, 2015). Ruang lingkup dalam penerapan $\mathrm{K} 3$ di laboratorium dapat meminimalkan resiko kecelakan kerja seperti potensi bahaya dari bahan kimia, biologi, fisik, radiasi serta musculoskeletal stresses (OSHA3404, 2011).

Dalam pengelolaan laboratorium telah disinggung syarat mutu laboratorium yang dapat disinkronisasikan dengan penerapan K3 seperti mengenai tata letak laboratorium, syarat ruang kantor, alat pelindung diri, kebersihan, peralatan darurat, mengenai bahan kimia, instalasi pembuangan limbah dan kelistrikan.

Laboratorium perlu melakukan K3 sehingga para penggunanya akan mendapatkan haknya seperti yang tertuang dalam undang-undang 
keselamatan dan kesehatan kerja. Penerapan K3 di laboratorium pendidikan memiliki tujuan umum sebagai beriku untuk melindungi tenaga laboratorium serta pengguna laboratorium lainnya dari resiko kerja saat beraktivitas di laboratorium, menciptakan kondisi yang aman baik itu peralatan dan bahan saat akan digunakan, mengkoordinasi setiap kegiatan yang ada di laboratorium berjalan dengan baik dan menumbuhkan lingkungan kerja yang nyaman dan aman. Hingga nantinya akan terjadi peningkatan produktvitas dan kesejahteraan bagi semua penggunanya (Mansyur, 2007).

Laboratorium Biologi merupakan sarana sebagai tempat melakukan berbagai praktikum yang berhubungan dengan bahan-bahan berbahaya yaitu bahan kimia dan biologi, menggunakan peralatan beraneka macam fungsi dan perlu daya dukung seperti penggunaan api, air dan listrik.

Hal inilah yang melatarbelakangi penelitian ini untuk mengetahui bagaimana penerapan K3 yang dilakukan di laboratorium biologi. Penerapan K3 ini dibuat dalam bentuk cek list yang meliputi ruang lingkup yang tertuang dalam peraturan perundang-undangan yang berlaku, diharapkan dengan adanya cek list nantinya sebagai tinjauan awal terhadap keselamatan dan kesehatan kerja merupakan bahan masukan dalam perencanaan dan pengembangan Sistem Manajemen K3 (International Labour Organization, 2013). Tujuan dari penelitian ini adalah untuk menganalisis cek list keselamatan dan kesehatan kerja yang ada di laboratorium biologi.

\section{Metode Penelitian}

Lokasi pengambilan data di Gedung D11 Laboratorium Biologi FMIPA UNNES meliputi 3 lantai dengan jumlah ruangan 14 laboratorium.

Metode dalam penelitian ini adalah metode deskriptif dalam bentuk survei. Survei dilakukan dengan kuisoner yang mengacu pada pada matrik acuan tabel 1 dimodifikasi dari Laboratory Safety Self-Assessment chek list Washington State University. Responden yang digunakan dalam penelitian ini adalah mahasiswa asisten praktikum dengan jumlah 18 orang.

Tabel 1. Matrik acuan cek list keselamatan dan kesehatan kerja

\begin{tabular}{ll}
\hline \multirow{2}{*}{ Tata letak } & Sub Indikator \\
\cline { 2 - 2 } Laboratorium & Tata letak ruangan \\
\cline { 2 - 2 } & Tata letak peralatan \\
\cline { 2 - 2 } & Ventiliasi \\
\hline
\end{tabular}

\begin{tabular}{|c|c|}
\hline & Pencahayaan \\
\hline & Ketersedian furnitur \\
\hline & $\begin{array}{l}\text { Kapasitas ruang untuk } \\
\text { kegiatan }\end{array}$ \\
\hline & Workstation/tempat kerja \\
\hline \multirow{6}{*}{$\begin{array}{l}\text { Kantor } \\
\text { Laboratorium }\end{array}$} & Sub Indikator \\
\hline & $\begin{array}{l}\text { Ruangan kantor dan } \\
\text { laboratorium terpisah }\end{array}$ \\
\hline & Tata letak ruangan \\
\hline & Ventilasi \\
\hline & Furnitur \\
\hline & Pencahayaan \\
\hline \multirow{5}{*}{$\begin{array}{l}\text { Alat Perlindungan } \\
\text { Diri (APD) }\end{array}$} & Sub Indikator \\
\hline & Jas laboratorium \\
\hline & Kaca mata pelindung \\
\hline & Sarung tangan \\
\hline & Sepatu pengaman \\
\hline \multirow{6}{*}{$\begin{array}{l}\text { Kebersihan } \\
\text { Laboratorium }\end{array}$} & Sub Indikator \\
\hline & Lantai \\
\hline & Bangku \\
\hline & Almari \\
\hline & Langit-langit \\
\hline & Rak \\
\hline \multirow{6}{*}{$\begin{array}{l}\text { Kebersihan Area } \\
\text { Kantor }\end{array}$} & Sub Indikator \\
\hline & Lantai \\
\hline & Almari \\
\hline & Langit-langit \\
\hline & Meja kerja \\
\hline & Rak \\
\hline \multirow{10}{*}{ Peralatan Darurat } & Sub Indikator \\
\hline & Pemadam kebakaran \\
\hline & $\begin{array}{l}\text { Pelatihan pemadaman } \\
\text { kebakaran }\end{array}$ \\
\hline & Kain Pemadam kebakaran \\
\hline & Fire Exits \\
\hline & First Aid Box \\
\hline & Eye Wash \\
\hline & Spill kits \\
\hline & Contact Person \\
\hline & Nomor darurat \\
\hline \multirow{5}{*}{ Bahan Kimia } & Sub Indikator \\
\hline & Jumlah \\
\hline & Penyimpanan \\
\hline & Labelling \\
\hline & Inventarisasi \\
\hline \multirow{3}{*}{$\begin{array}{l}\text { Pelarut / Cairan } \\
\text { Mudah-menyala }\end{array}$} & Sub Indikator \\
\hline & Jumlah \\
\hline & Penyimpanan \\
\hline \multirow{3}{*}{ Limbah Cair } & Sub Indikator \\
\hline & Jumlah \\
\hline & Penyimpanan \\
\hline \multirow{3}{*}{$\begin{array}{l}\text { Alat Gelas/Benda } \\
\text { Tajam }\end{array}$} & Sub Indikator \\
\hline & Jumlah \\
\hline & Penyimpanan \\
\hline \multirow{2}{*}{$\begin{array}{l}\text { Limbah Alat Gelas } \\
\text { /Bahan sekali }\end{array}$} & Sub Indikator \\
\hline & Jumlah \\
\hline
\end{tabular}




\begin{tabular}{ll}
\hline pakai & Tempat Pembuangan \\
\hline \multirow{4}{*}{ Kelistrikan } & Sub Indikator \\
\cline { 2 - 2 } & Daya listrik \\
\cline { 2 - 2 } & Setting kabel \\
\cline { 2 - 2 } & Keamanan kelistrikan \\
\hline
\end{tabular}

Identifikasi responden berdasarkan jenis kelamin dapat dilihat pada grafik 1. Dimana proporsi terbesar berjenis kelamin wanita.

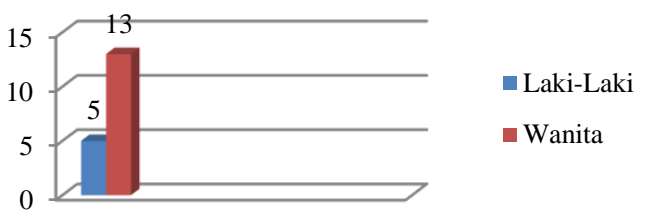

Gambar 1. Grafik data responden berdasarkan jenis kelamin

Pemilihan responden adalah asisten praktikum dikarena mereka telah belajar praktikum lebih dulu dan telah mengenal laboratoium lebih lama dibandingkan dengan mahasiswa yang baru ikut praktikum. Dilihat dari porposi jumlah kehadiran di laboratorium, mereka lebih unggul yaitu dulu waktu praktikum, persiapan asisten praktikum, asistensi praktikum, dan koreksi hasil praktikum.

Analisis data dilakukan dengan pemberian nilai positif pada pernyataan yang dibuat untuk kuisioner tabel 2.

Tabel 2. Kriteria pemberian skor pernyataan positif

\begin{tabular}{ll}
\hline Pernyataan & Skor \\
\hline Selalu & 4 \\
\hline Sering & 3 \\
\hline Kadang-kadang & 2 \\
\hline Tidak pernah & 1 \\
\hline
\end{tabular}

Penyimpulan empat kategori dengan teori distribusi normal tabel 3 (Sugiyono, 2008).

Tabel 3. Uji Normatif

\begin{tabular}{|c|c|c|c|}
\hline No & $\begin{array}{l}\text { Rentan } \\
\text { Normal }\end{array}$ & Kategori & $\begin{array}{l}\text { Skor } \\
\text { kategori }\end{array}$ \\
\hline 1 & $\mathrm{x} \geq \mathrm{M}+1,5 \mathrm{SD}$ & $\begin{array}{l}\text { Sangat } \\
\text { baik }\end{array}$ & $x \geq 67,5$ \\
\hline 2 & $\begin{array}{l}\mathrm{M}<\mathrm{x}<\mathrm{M}+1,5 \mathrm{~S} \\
\mathrm{D}\end{array}$ & Baik & $\begin{array}{l}45 \leq x<6 \\
7,5\end{array}$ \\
\hline 3 & $\begin{array}{l}\text { M- } \\
1,5 \mathrm{SD} \leq \mathrm{x}<\mathrm{M}\end{array}$ & $\begin{array}{l}\text { Cukup } \\
\text { baik }\end{array}$ & $\begin{array}{l}22,5 \leq \mathrm{x}< \\
45\end{array}$ \\
\hline 4 & $M-1,5 S D \geq x$ & Tidak baik & $22,5 \geq x$ \\
\hline
\end{tabular}

Keterangan :

$$
\begin{aligned}
\mathrm{M} & =\text { Mean } \\
& =1 / 2(\text { maksimal }+ \text { minimal }) \\
\mathrm{SD} & =\text { Standar Deviasi } \\
& =1 / 6(\text { maksimal+minimal })
\end{aligned}
$$

Selanjutnya persentase untuk mencari besarnya persentase digunakan rumus persentase :

$P=\frac{F}{N} x 100 \%$

Keterangan :

$\mathrm{P}=$ Persentase

$\mathrm{F} \quad=$ Skor yang diperoleh

\section{Hasil dan Pembahasan}

Analisis cek list keselamatan dan kesehatan kerja di laboratorium

1. Indikator Layout Laboratorium

Sebuah laboratorium harus dirancang efisien sehingga membuat penggunanya terjaga kesehatan dan kesejahteraannya. Skor yang diperoleh untuk indikator layout laboratorium terlihat pada tabel 4 , dengan rata-rata perolehan skor 62.7 tergolong kategori baik. Keselamatan harus tetap dikedepankan dalam laboratorium serta diimbangi dengan kenyamanan pengguna.

Kenyamanan berkaitan dengan pengaturan suhu dan aliran udara yang sesuai, hingga berimbas pada produktivitas pengguna laboratorium. Penggunaan ventilasi udara mengunakan prinsip dasar yaitu udara masuk harus ama dengan dengan udara yang keluar. Hal inilah yang membuat udara di dalam ruang akan tetap terjaga dengan baik (Cooper, 1994). Laboratorium harus memiliki sistem ventilasi umum guna mengendalikan kuantitas dan kualitas udara yang dipasok dan dibuang. Penggantian udara ini harus terus menerus sehingga konsentrasi zat beracun atau toksik tidak meningkat selama hari kerja dan juga tidak disirkulasikan ulang dari laboratorium satu ke laboratorium yang lain (Committee on Promoting Safe and Secure Chemical Management in Developing Countries \& Studies, 2011).

Untuk pencahayaan dengan kriteria tidak menyilaukan mata, tidak menimbulkan panas berlebih, tidak menghasilkan gas, tidak menimbulkan bayangan kontras, tidak berkedip-kedip dan pencahayaan merata keseluruh ruangan (Soleman \& Sitania D, 2011). Pada ketersedian furniture salah satunya pada bangku untuk melakukan kegiatan, dimana harus sesuai dengan standar nasional Indonesia. Ketentuan yang digunakan yaitu kegiatan yang membutuhkan presisi: tinggi bangku harus berada di atas siku, kerja ringan : tinggi bangku harus tepat di bawah siku dan kerja berat: tinggi bangku harus 4-6 inci di bawah siku (Phuspa, 2017).

Unit laboratorium yang ada di laboratorium biologi memiliki kapasitas ruang yang cukup ideal sebagai tempat praktikum yaitu 2,5 $\mathrm{m}^{2}$ / praktikan telah terpenuhi. 
Kemudian untuk ruang persiapan dan penyimpanan telah tersedia meskipun luasnya belum semuanya memenuhi standar yang ada yaitu $20 \mathrm{~m}^{2}$.

Tabel 4. Skor indikator layout laboratorium

\begin{tabular}{llrr}
\hline & $\begin{array}{l}\text { Sub } \\
\text { Indikator }\end{array}$ & Skor & Mean \\
\cline { 2 - 4 } & $\begin{array}{l}\text { Tata letak } \\
\text { ruangan }\end{array}$ & 66 & 45 \\
\cline { 2 - 4 } & $\begin{array}{l}\text { Tata letak } \\
\text { peralatan }\end{array}$ & 66 & 45 \\
\cline { 2 - 4 } Layout Lab & Ventiliasi & 68 & 45 \\
\cline { 2 - 4 } & Pencahayaan & 65 & 45 \\
\cline { 2 - 4 } & $\begin{array}{l}\text { Ketersedian } \\
\text { furnitur }\end{array}$ & 58 & 45 \\
\cline { 2 - 4 } & $\begin{array}{l}\text { Kapasitas } \\
\text { ruang untuk } \\
\text { kegiatan }\end{array}$ & & \\
\cline { 2 - 4 } & $\begin{array}{l}\text { Workstation } \\
\text { /tempat } \\
\text { kerja }\end{array}$ & & 45 \\
\hline & Rata-rata & 62.7 & 45 \\
\hline
\end{tabular}

2. Indikator Kantor Laboratorium

Hampir semua pekerja laboratorium membutuhkan ruang penunjang kantor yang berada di dekat laboratorium. Bila memungkinkan, semua kantor di luar ruang laboratorium untuk memungkinkan ruang kerja yang lebih aman dan lebih tenang. Tempatkan zona kantor berdekatan dengan laboratorium agar memudahkan akses dan komunikasi (Committee on Promoting Safe and Secure Chemical Management in Developing Countries \& Studies, 2011). Skor yang didapat dari indikator ini terlihat pada tabel 5. Dari rata-rata menurut uji normatif masuk kategori baik dengan skor 65.6 .

Tabel 5. Skor indikator kantor laboratorium

\begin{tabular}{llrr}
\hline & \multicolumn{1}{l}{ Sub Indikator } & Skor & Mean \\
\cline { 2 - 4 } & $\begin{array}{l}\text { Ruangan } \\
\text { kantor dan }\end{array}$ & & \\
Kantor & $\begin{array}{l}\text { laboratorium } \\
\text { terpisah }\end{array}$ & 72 & 45 \\
\cline { 2 - 4 } & $\begin{array}{l}\text { Tata letak } \\
\text { ruangan }\end{array}$ & 64 & 45 \\
\cline { 2 - 4 } & Ventilasi & 62 & 45 \\
\cline { 2 - 4 } & Furnitur & 64 & 45 \\
\cline { 2 - 4 } & Pencahayaan & 66 & 45 \\
\hline & Rata-rata & 65.6 & 45 \\
\hline
\end{tabular}

3. Indikator Alat Pelindung Diri (APD)

Pelindung Diri (APD) adalah suatu alat yang mempunyai kemampuan untuk melindungi seseorang dengan fungsi mengisolasi sebagian atau seluruh tubuh dari potensi bahaya ditempat kerja (Kemnakertrans
RI). Dari indikator ini dengan sub indikator berupa jas laboratorium, kaca mata pelindung, sarung tangan dan sepatu pengaman mendapat skor seperti terlihat pada tabel 6. Skor rata-rata pada indikator ini masuk dalam kategori baik menurut uji normatif. Kecenderungan bagi pengguna laboratorium adalah ketidaktauan dalam pentingnya APD dan kesadaran menggunakan APD. Sikap profesionalisme para praktikan di laboratorium dapat dilihat dari pemahaman prinsip dan prosedur kerja yang dilakukan (Hati, 2015).

Tabel 6. Skor indikator Alat pelindung diri

\begin{tabular}{llrr}
\hline \multirow{4}{*}{ APD } & Sub Indikator & Skor & Mean \\
\cline { 2 - 4 } & Jas laboratorium & 72 & 45 \\
\cline { 2 - 4 } & $\begin{array}{l}\text { Kaca mata } \\
\text { pelindung }\end{array}$ & 27 & 45 \\
\cline { 2 - 4 } & Sarung tangan & 61 & 45 \\
\cline { 2 - 4 } & $\begin{array}{l}\text { Sepatu } \\
\text { pengaman }\end{array}$ & 33 & 45 \\
\hline & Rata-rata & 48.25 & 45 \\
\hline
\end{tabular}

Keempat sub indikator yang ada terdapat dua poin yang memperoleh nilai dibawah skor rata-rata yaitu kaca mata pelindung dan sepatu pengaman. Ternyata dari unit laboratorium yang ada di biologi hanya satu unit yang memiliki kaca pelindung dan sepatu pengaman yang bisa digunakan pada proses pelaksanaan kegiatan di laboratorium. Penggunaan kaca pelindung tersebut digunakan untuk melindungi mata saat menggunakan peralatan dan bahan yang memiliki resiko pemaparan pada mata. Seperti pada saat menggunakan biohazard harus menggunakan APD berupa kacamata splash, sarung tangan, masker bedah tahan cairan, jas laboratorium, celemek dan penutup lengan (University of washington, 2016).

Sedangkan untuk sepatu pengaman digunakan untuk isolasi terhadap paparan kemungkinan pecahan alat gelas di lantai laboratorium dan juga resiko pemaparan. Seperti saat menggunakan bahan kimia harus menggunakan APD berupa sarung tangan, pakaian tahan bahan kimia, celemek, penutup lengan dan sepatu, kacamata; jas laboratorium (University of washington, 2016). Salah satu bentuk pencegahan yang paling mendasar terhadap segala bahaya kontaminasi dan bahan kimia yang digunakan selama berkegiatan di laboratorium adalah dengan menggunakan APD (B Amertha Putra Manuaba (Program Studi Pendidikan Dokter, 2016).

4. Indikator Kebersihan Laboratorium

Factor kebersihan merupakan hal yang penting berhubungan dengan kenyaman dan kesehatan bagi pengguna laboratorium. Lantai dai laboratorium harus dijaga sejajar supaya 
tidak terjadi perbedaan ketinggian yang menyebabkan kecelakan berupa jatuh terjadi. Lantai laboratorium harus bersih dari tumpahan dan tidak licin, karena berpotensi terhadap adanya kecelakaan kerja (University of washington, 2016). Di laboratorium biologi skor untuk indikator kebersihan laboratorium masuk dalam kategori baik dengan nilai 63,6 (Tabel 7).

Tabel 7. Skor indikator kebersihan laboratorium

\begin{tabular}{llrr}
\hline \multirow{4}{*}{$\begin{array}{l}\text { Kebersihan } \\
\text { Lab }\end{array}$} & $\begin{array}{l}\text { Sub } \\
\text { Indikator }\end{array}$ & Skor & Mean \\
\cline { 2 - 4 } & Lantai & 69 & 45 \\
\cline { 2 - 4 } & Bangku & 65 & 45 \\
\cline { 2 - 4 } & Almari & 57 & 45 \\
\cline { 2 - 4 } & Langit-langit & 62 & 45 \\
\cline { 2 - 4 } & Rak & 65 & 45 \\
\hline & Rata-rata & 63.6 & 45 \\
\hline
\end{tabular}

5. Indikator Kebersihan Kantor Laboratorium

Kebersihan ruang kantor ini untuk meningkatkan kinerja dari tenaga laboratorium dalam memberikan layanan terhadap pengguna laboratorium, karena berhubungan dengan kenyaman yang diperoleh. Peningkatan kinerja akan berpengaruh terhadap layanan yang diberikan. Kategori yang didapat dari skor 62,4 (Tabel 8) adalah kebersihan kantor laboratorium termasuk baik.

Tabel 8. Skor indikator kantor laboratorium

\begin{tabular}{llrr}
\hline \multirow{4}{*}{$\begin{array}{llrr}\text { Area } \\
\text { Kantor }\end{array}$} & Sub Indikator & Skor & Mean \\
\cline { 2 - 4 } & Lantai & 68 & 45 \\
\cline { 2 - 4 } & Almari & 55 & 45 \\
\cline { 2 - 4 } & Langit-langit & 70 & 45 \\
\cline { 2 - 4 } & Meja kerja & 58 & 45 \\
\cline { 2 - 4 } & Rak & 61 & 45 \\
\hline & Rata-rata & 62.4 & 45 \\
\hline
\end{tabular}

6. Indikator Alat Keselamatan

Pada indikator ini masuk dalam ketagori baik secara keseluruhan dari 9 sub indikator yaitu 48,44 (Tabel 9). Namun dari sub indikator yang ada terdapat tiga item yang berada di bawah rata-rata skor yang ada yaitu pelatihan pemadaman kebakaran, kain pemadam kebakaran dan petunjuk jalur keluar saat terjadi kebakaran. Ketiga faktor inilah yang perlu ditingkatkan dan diadakan secara rutin. Dalam keselamatan dan kesehatan kerja perlu dilakukan pelatihan dan pendidikan dalam menggunakan peralatan keamanan supaya bila terjadi kecelakan kerja minimal mengetahui cara penggunaan alat keselamatan sederhana yang telah tersedia.

Tujuan utama dilakukan pendidikan dan pelatihan adalah mengerti, pengetahuan tingkat dasar, bahaya kesehatan yang terdapat di lingkungan kerjanya; terbiasa dengan prosedur kerja dan melakukan pekerjaan sesuai prosedur untuk mengurangi tingkat pajanan serta menggunakan alat pelindung diri dengan benar dan memelihara agar tetap berfungsi baik (Mansyur, 2007).

Tabel 9. Skor indikator alat keselamatan

\begin{tabular}{llrr}
\hline & Sub Indikator & Skor & Mean \\
\cline { 2 - 4 } & $\begin{array}{l}\text { Pemadam } \\
\text { kebakaran }\end{array}$ & 61 & 45 \\
\cline { 2 - 4 } & $\begin{array}{l}\text { Pelatihan } \\
\text { pemadaman }\end{array}$ & & \\
kebakaran & 41 & 45 \\
\cline { 2 - 4 } Peralatan & Kain Pemadam & & \\
& kebakaran & 38 & 45 \\
\cline { 2 - 4 } & Fire Exits & 34 & 45 \\
\cline { 2 - 4 } & First Aid Box & 56 & 45 \\
\cline { 2 - 4 } & Eye Wash & 61 & 45 \\
\cline { 2 - 4 } & Spill kits & 46 & 45 \\
\cline { 2 - 4 } & Contact Person & 52 & 45 \\
\cline { 2 - 4 } & Nomor darurat & 47 & 45 \\
\hline Rata-rata & 48.4 & 45 \\
\hline
\end{tabular}

7. Indikator Bahan Kimia

Laboratorium banyak menggunakan bahan yang berpotensi bahaya meliputi bahan kimia, bahan radioaktif dan agen biologis menular. Bahan-bahan ini dapat dimanipulasi setiap hari sebagai bagian eksperimen, penelitian atau produksi (Cooper, 1994). Pada indikator ini melihat skor yang ada di tabel 10 termasuk dalam kategori baik. Bahan kimia merupakan ancaman berbahaya baik secara fisik dan/atau kesehatan para pekerja di bidang klinis, industri, dan laboratorium akademik. Bahan kimia laboratorium termasuk agen penyebab kanker (karsinogen), toksin (misalnya : yang mempengaruhi hati, ginjal, dan sistem saraf), iritan, korosif, sensitizer, dan juga agen yang bekerja pada sistem darah atau merusak paruparu, kulit, mata, atau selaput lendir. OSHA mengatur kurang lebih sekitar 400 zat yang berpontesi bahaya bagi fisik dan/atau kesehatan (OSHA3404, 2011).

Oleh karena itu diharapkan dalam sebuah laboratorium harus memenuhi standar laboratorium yang terlindungi dan aman untuk bekerja. Elemen utama dalam standar laboratorium menurut (OSHA3404, 2011) terdiri atas 5 item yaitu identifikasi bahaya; rencana kebersihan bahan kimia; informasi dan pelatihan; monitoring pemaparan; dan konsultasi dan pemeriksaan medis.

Tabel 10. Skor indikator bahan kimia

\begin{tabular}{llrr}
\hline \multirow{3}{*}{ Bahan } & Sub Indikator & Skor & Mean \\
\cline { 2 - 4 } Kimia & Jumlah & 63 & 45 \\
\cline { 2 - 4 } & Penyimpanan & 56 & 45 \\
\cline { 2 - 4 } & Labelling & 58 & 45 \\
\hline
\end{tabular}




\begin{tabular}{lrr}
\hline Inventarisasi & 61 & 45 \\
\hline Rata-rata & 59.5 & 45 \\
\hline
\end{tabular}

8. Indikator Larutan Kimia mudah menyala

Setiap laboratorium harus mengidentifikasi bahaya dari bahan kimia yang akan ada. Pemberian label di wadah bahan kimia harus jelas. Pemberian label ini harus memenuhi persyaratan pelabelan dan laboratorium melarang menggunakan dan menyimpan zat berbahaya di laboratorium tanpa label yang jelas. Kategori bahan kimia yang mudah menyala atau criteria lain telah ada dalam MSDS (Material Safety Data Sheets).

Menurut hasil yang ada untuk kategori ini masuk dalam kategori baik dengan skor 63 (tabel 11). Dalam lembaran memuat tentang : nama bahan kimia; informasi produsen; bahan berbahaya/informasi identitas; karakteristik fisik / kimia; data bahaya kebakaran dan ledakan; data reaktivitas; data bahaya kesehatan; tindakan pencegahan untuk penanganan dan penggunaan yang aman; dan tindakan pengendalian (OSHA3404, 2011). Perlakuan yang diberikan pada bahan kimia yang mudah menyala ini antara lain penyimpanan di lemari dengan pengaman yang disetujui. Jangan simpan bahan yang tidak kompatibel di kabinet yang sama. Jauhkan dari sumber pengapian: panas, percikan api, atau api terbuka. Padatan mudah terbakar harus dipisahkan dari cairan yang mudah terbakar (University of washington, 2016).

Tabel 11. Skor indikator larutan kimia

\begin{tabular}{llrr}
\hline \multirow{2}{*}{$\begin{array}{l}\text { Larutan } \\
\text { Kimia }\end{array}$} & $\begin{array}{l}\text { Sub } \\
\text { Indikator }\end{array}$ & Skor & Mean \\
\cline { 2 - 4 } & Jumlah & 63 & 45 \\
\cline { 2 - 4 } & Penyimpanan & 63 & 45 \\
\hline & Rata-rata & 63 & 45 \\
\hline
\end{tabular}

9. Indikator Limbah Kimia

Limbah merupakan bahan sisa yang telah terpakai, karena disini berhubungan dengan bahan kimia maka limbah yang dihasilkan juga merupakan limbah bahan kimia. Pembuangan limbah bahan kimia ini merupakan hal yang vital di laboratorium. Pembuangan yang benar harus memperhatikan informasi mengenai sifat limbah dari identifikasi semua bahan kimia. Semua informasi tersebut pasti telah tercantum didalam label yang ada di bahan kimia tersebut.

Untuk pembuangan limbah kimia ini harus mempertimbangan keselamatan pengguna laboratorium. Aturan secara umum dalam penangganan limbah laboratorium adalah menggunakan wadah container untuk menampung limbah disertai dengan label mengenai limbah yang ada di dalamnya, mencampur beberapa limbah yang kompatibel sehingga mengurangi wadah penyimpanan, pelabelan wadah dengan informasi mengenai jumlah dan sifat bahan, pemilihan wadah yang tepat untuk jenis bahan kimia, mengikuti aturan jumlah kapsitas penampungan limbah dan jangka waktu penyimpanan, serta membersihkan wadah dari kontaminasi (Committee on Promoting Safe and Secure Chemical Management in Developing Countries \& Studies, 2011). Untuk indikator ini mendapat skor 56 dengan masuk dalam kategori baik (Tabel 12). Hal ini menunjukan telah terdapat pengelolaan penampungan limbah kimia, meskipun belum sempurna dan perlu peningkatan lagi.

Tabel 12. Skor indikator limbah kimia

\begin{tabular}{llrr}
\hline \multirow{2}{*}{$\begin{array}{l}\text { Limbah } \\
\text { Cair }\end{array}$} & Sub Indikator & Skor & Mean \\
\cline { 2 - 4 } & Jumlah & 58 & 45 \\
\cline { 2 - 4 } & Penyimpanan & 54 & 45 \\
\hline & Rata-rata & 56 & 45 \\
\hline
\end{tabular}

10. Indikator Alat Gelas

Laboratorium biologi merupakan tempat berbagai aktivitas praktikum, penelitian dan pengabdian yang tidak lepas dari penggunaan alat-alat gelas. Oleh karena itu jumlah alat gelas yang digunakan pasti dalam jumlah besar dan laboratorium telah menyediakan alat gelas yang cukup untuk mencukupi kebutuhan yang ada. Ini terbukti untuk jumlah alat gelas mendapat skor 65 diatas rata-rata yang ada (Tabel 13).

Untuk tempat penyimpanan alat gelas sendiri telah disediakan lemari khusus agar peralatan tersimpan dengan baik dan mudah pencariannya. Aturan yang harus diingat saat menggunakan alat gelas yaitu segera perbaiki atau ganti alat gelas yang rusak, menggunakan alat pelindung tangan saat menggunakan alat gelas yang rentan pecah, gunakan sarung tangan saat memebersihan alat gelas yang pecah, perhatikan dan baca petunjuk pemakain alat gelas yang spesifik atau khusus, kumpulkan pecahan alat gelas pada plastic berlabel atau container metal dan jangan dicampur dengan sampah lainnya.

Tabel 13. Skor indikator alat gelas

\begin{tabular}{llrr}
\hline \multirow{2}{*}{ Alat Gelas } & $\begin{array}{l}\text { Sub } \\
\text { Indikator }\end{array}$ & Skor & Mean \\
\cline { 2 - 4 } & Jumlah & 65 & 45 \\
\cline { 2 - 4 } & Penyimpanan & 62 & 45 \\
\hline & Rata-rata & 63.5 & 45 \\
\hline
\end{tabular}

11. Indikator Limbah Alat Gelas 
Resiko penggunaan alat gelas adalah pecah menjadi beberapa bagian besar dan kecil. Limbah alat gelas termasuk kedalamnya barang plastik diartikan sebagai barang yang tidak dapat didegradasi secara langsung dan memiliki resiko dalam penanganannya. Yang termasuk kedalam limbah alat gelas yaitu pecahan alat gelas, wadah bahan kimia yang kosng, pisau bedah dan alat gelas yang rawan pecah (seperti pipet tetes, obyek glas dan kaca penutup) (University of washington, 2016).

Masukkan limbah alat gelas kedalam kardus yang kuat dan dilapisi plastic. Berat limbah yang ditampung dalam satu kotak tidak boleh lebih dari $11 \mathrm{~kg}$ serta diberi label yang jelas meliputi nama laboratorium dan jenis limbahnya. Di laboratorium telah disediakan tempat khusus untuk menampung limbah alat gelas meskipun masih berupa wadah plastic dengan label penanda, sehingga skor yang dipeoleh termasuk dalam kategori baik yaitu 54 (tabel 14).

Tabel 14. Skor indikator limbah alat gelas

\begin{tabular}{llrr}
\hline \multirow{2}{*}{$\begin{array}{l}\text { Limbah } \\
\text { Alat Gelas }\end{array}$} & $\begin{array}{l}\text { Sub } \\
\text { Indikator }\end{array}$ & Skor & Mean \\
\cline { 2 - 4 } & Jumlah & 56 & 45 \\
\cline { 2 - 4 } & $\begin{array}{l}\text { Tempat } \\
\text { Pembuangan }\end{array}$ & 52 & 45 \\
\hline & Rata-rata & 54 & 45 \\
\hline
\end{tabular}

12. Indikator Kelistrikan

Listrik merupakan factor penunjang utama dalam kegiatan yang ada di laboratorium sebab hampir semua peralatan memerlukan arus listrik untuk bekerja. Bahaya dan tidaknya sentuhan langsung atau sentuhan tidak langsung pada instalasi listrik tergantung dari tegangan, arus, waktu serta kondisi badan manusia. Umumnya kebakaran karena listrik disebabkan adanya pembebanan berlebihan, terdapat sambungan tidak sempurna, penggunaan perlengkapan tidak standar, pembatas arus tidak sesuai, terjadinya kebocoran isolasi serta adanya sambaran petir (Soleman \& Sitania D, 2011).

Di laboratorium biologi untuk sub indikator kelistrikan mendapat skor yang tertera di tabel 15. Rata-rata skor ada diangka 40.33 ini termasuk kedalam kategori cukup baik. Pada indikator ini perlu mendapatkan perhatian khusus, sebab factor penunjang utama ini sangat vital bagi laboratorium.

Tabel 15. Skor indikator kelistrikan

\begin{tabular}{llrr}
\hline \multirow{4}{*}{ Kelistrikan } & Sub Indikator & Skor & Mean \\
\cline { 2 - 4 } & Daya listrik & 43 & 45 \\
\cline { 2 - 4 } & Setting kabel & 40 & 45 \\
\cline { 2 - 4 } & $\begin{array}{l}\text { Keamanan } \\
\text { kelistrikan }\end{array}$ & 38 & 45 \\
\hline
\end{tabular}

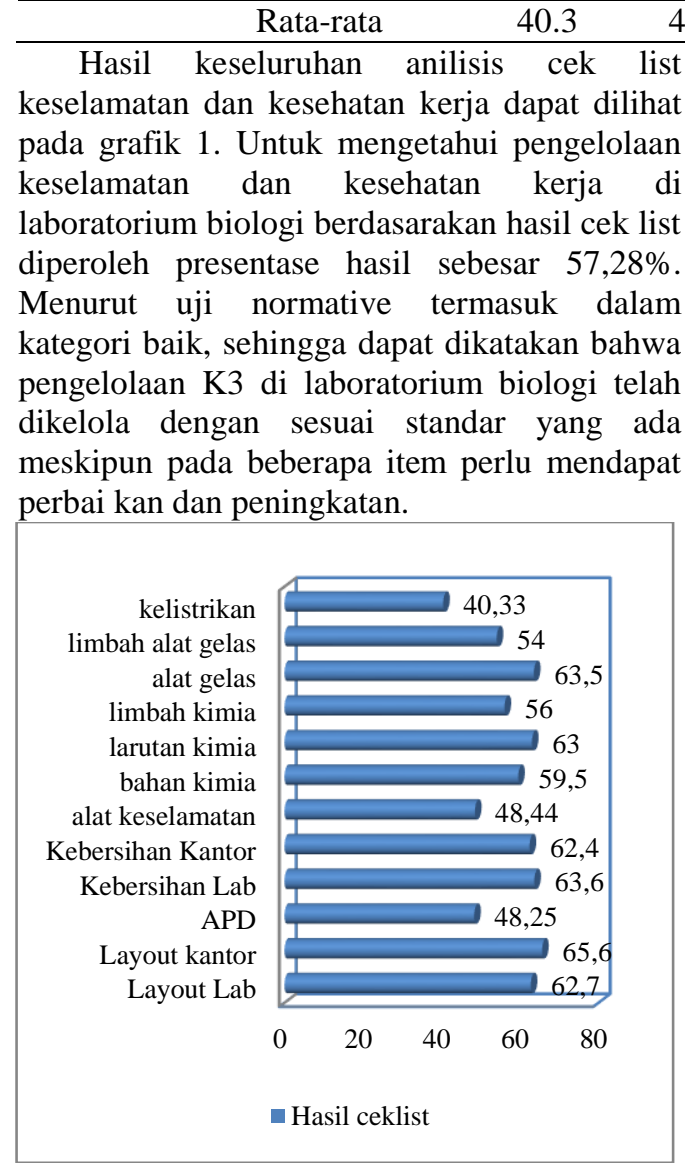

Grafik 1. Hasil Cek list secara keseluruhan

\section{Kesimpulan}

Berdasarkan analisis mengenai cek list keselamatan dan kesehatan kerja di laboratorium biologi menurut uji normatif masuk dalam kategori baik. Hal ini menunjukan bahwa penerapan kesehatan dan keselamatan kerja telah dilaksanakan berdasarkan pada indikator matrik keselamatan dan kesehatan kerja.

\section{Ucapan Terima Kasih}

Penulis mengucapkan terima kasih kepada :

1.LP2M dan Laboratorium Biologi Fakultas Matematika dan Ilmu Pengetahuan Alam UNNES.

2. Kepala laboratorium, PLP dan teknisi yang ada di laboratorium Biologi FMIPA UNNES

\section{Daftar Pustaka}

B Amertha Putra Manuaba (Program Studi Pendidikan Dokter, U. S. R. M. ). (2016). Prosedur Penggunaan Alat Perlindungan Diri Dan BIOSAFETY Level 1 Dan 2. ISM (Intisari Sains Medis), 6(1), 117-123. 
Committee on Promoting Safe and Secure Chemical Management in Developing Countries, B. on C. S. and T., \& Studies, D. on E. and L. (2011). Chemical Laboratory Safety and Security: A Guide to Prudent Chemical Management, 281. Retrieved from http://dels.nas.edu/resources/staticassets/bcst/miscellaneous/Chemical-Laboratory-

Safety-and-Security.pdf

Cooper, E. C. (1994). Laboratory Design Handbook, 256. https://doi.org/10.1016/00160032(51)90016-6

Hati, S. W. (2015). Analisis Keselamatan Dan Kesehatan Kerja (K3) Pada Pembelajaran Di Laboratorium Program Studi Teknik Mesin POLITEKNIK NEGERI BATAM. Prosiding SNE", Pembangunan Manusia Melalui Pendidikan Dalam Menghadapi ASEAN Economic Community 2015'. International Labour Organization. (2013). Keselamatan dan Kesehatan Kerja Keselamatan dan Kesehatan Sarana untuk Produktivitas. Retrieved from www.ilo.org

Mansyur, M. (2007). Manajemen Risiko Kesehatan di Tempat Kerja. Majalah Kedokteran, 57(September), 1-5. Retrieved from http://scholar.googleusercontent.com/scholar?q=cac he:mfRwkLviF3cJ:scholar.google.com/+epidemiol ogi+kesehatan+kerja\&hl=id\&as_sdt=0,5\&as_vis=1 OSHA3404. (2011). Laboratory Safety Guidance. Occupational Safety and Health Administration, 3404-11R.

Phuspa, S. M. (2017). Hubungan Resiko Ergonomi dengan Kejadian Musculosceletal Disorder pada Pengguna Laboratorium Teknologi Pertanian Universitas X. IJHS, 1(1), 30-36.

Soleman, A., \& Sitania D, F. (Fakultas T. (2011). Pedoman Kesehatan Dan Keselamatan Kerja Pada. Arika, 5(2), 125-136.

Sugiyono. (2008). Metode Penelitian Kuantitatif Kualitatif dan R\&D. Alfabeta. Bandung.

University of washington. (2016). Laboratory Safety Manual, (October). Amerika Serikat : University of washington. 